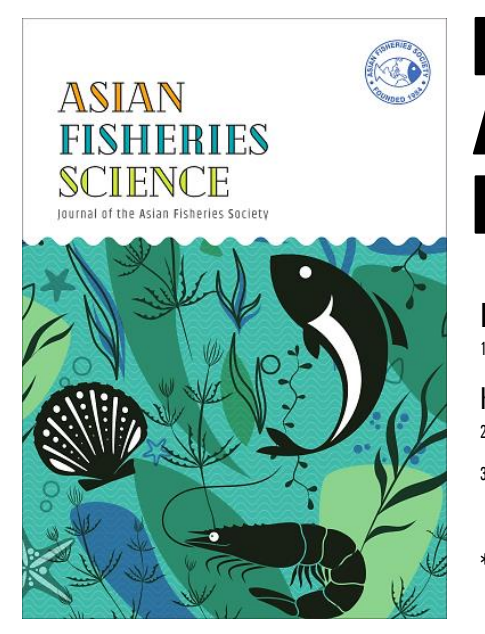

\title{
Bioeconomic Approach for Assessing Status of Trawl Fishery in the Straits of Malacca
}

\author{
HOONG SANG WONG ${ }^{1, *}$, CHEN CHEN YONG ${ }^{2}$, AZMAH OTHMAN ${ }^{3}$ \\ 'Department of Management Studies, UCSI University, UCSI Heights, 1 Jalan Menara Gading, Taman Connaught, 56000 Cheras, \\ Kuala Lumpur, Malaysia \\ 2Department of Economics, University of Malaya, Kuala Lumpur, Malaysia \\ ${ }^{3}$ Department of Development Studies, University of Malaya, Kuala Lumpur, Malaysia
}

*E-mail: hswong001@yahoo.com |Received: 26/07/2021; Accepted: 27/12/2021

(c) Asian Fisheries Society

Published under a Creative Commons

license

E-ISSN: 2073-3720

https://doi.org/10.33997/j.afs.2021.34.4.010

\section{Abstract}

The Straits of Malacca provides half of Malaysia's total marine fish and seafood supply. Due to depleted fish stock, the Malaysian Government has established a comprehensive legal framework to reduce overfishing in the Straits over the last five decades. However, there are limited scientific studies on the current status of stock recovery. This paper aims to use bioeconomic approach to determine the current trawl fishery status in the Straits. Various statistical tests showed that the Clarke-Yoshimoto-Pooley model was better than the Schnute model in predicting and thus used to estimate the crucial bioeconomic parameters. The current yield and standardised effort of 239,692 tonnes and 931,692 standard fishing days were very close to the estimated biological maximum sustainable yield (239,915 tonnes) and above $18 \%$ of the standardised effort $(763,649$ standard fishing days) to achieve it. The maximum economic yield was estimated at 201,542 tonnes while the corresponding standardised effort was 396,799 standard fishing days indicating serious economic overfishing in the Straits. If the current effort can be reduced by $57 \%$, fish biomass and economic rent will increase by $97 \%$ and $835 \%$, respectively. A price sensitivity analysis predicted that demand-pull fish price inflation could exacerbate the overfishing problem, particularly under unrestrained environment. A $50 \%$ increase in price could lead to a $132 \%$ increase in fishing effort from the base case. The findings of this paper provide valuable insights for fishery managers to refine their existing fishery management program to achieve sustainable fishery for the future.

Keywords: sustainable fishery, maximum sustainable yield, demersal, trawl, maximum economic yield

\section{Introduction}

The Straits of Malacca is traditionally an important fishery ground which accounts for half of the total marine landings in Malaysia. The most common commercial fishing gear types are the trawl net and purse seine. The Department of Fisheries Malaysia (DOFM, 2020) reported 2018 annual total fisheries catch from the Straits of Malacca at around 788,000 tonnes, valued at MYR6.7 billion (USD1.6 billion). In the same year, Commercial trawl fishing accounted for slightly more than half of the total fisheries landings; the annual total trawl landings were recorded at more than 235,000 tonnes comprising demersal finfish (82 $\%)$ and shellfish (18\%). Since the late 1970s, trawl fishery in the Straits of Malacca has been overexploited, a decade after the introduction of commercial trawlers in the mid-1960s (Wong and Yong, 2020). To protect the marine resources, particularly from the trawl fishery, the Department of Fisheries Malaysia (DOFM) has gazetted and implemented several regulatory policies that included a zoning system in 1981 that allows or prohibits traditional and commercial fishing in coastal waters. The zoning system, which includes an A zone ( $0-5 \mathrm{~nm})$, B zone $(5-12 \mathrm{~nm}), \mathrm{C}$ zone $(12-30 \mathrm{~nm})$, and $D$ zone (beyond $30 \mathrm{~nm}$ ), restricts larger commercial trawlers to more offshore waters while protecting fisheries resources and traditional fishing in nearshore waters (Ramli, 2015).

The effectiveness of this zoning system in terms of 
protecting the fisheries resources is, however, unknown. Did fishery managers manage to reduce fishing efforts and promote the restoration of the depleted fish stock in the Straits of Malacca? To answer this question, we can compare current effort, catch, and biomass against the estimated bioeconomic parameters in the Straits. Therefore, the objective of this paper is to deal with three critical questions: i) Which of the two popularly used biological models, the Schnute model and the ClarkeYoshimoto-Pooley (CYP) model, is suitable for bioeconomic parameter estimations in fisheries? ii) Have the current effort and catch exceeded the estimated bioeconomic parameters? iii) What is the magnitude of the impact of future cost and price inflation on the commercial fishing exploitation rate? To answer these questions, this study used the catch and effort data (1981-2018) of the trawl fisheries fitted to two established surplus production models (SPM), the CYP and Schnute models, to generate the required parameters for a bioeconomic analysis of the fishery (Clarke et al., 1992). This paper treated the trawl fishery as one aggregated stock. The biological parameters of the best performing SPM model were estimated from the annual time series data in the protected fishing zone $(5-30 \mathrm{~nm})$, the most popular fishing region, and then combined with price and cost data to develop the bioeconomic model. Important biological and economic parameters such as maximum sustainable yield (MSY), maximum economic yield (MEY), and economic rent will be estimated using the newly developed bioeconomic model. Cost and price inflation sensitivity analysis will be conducted on the bioeconomic parameters as well. The last part of the paper will discuss the results of the bioeconomic model and their implications for the trawl fishery in the Straits of Malacca.

\section{Materials and Methods}

\section{The model}

This paper examined two well-known surplus production models, namely Schnute and CYP models, and identifies the best production approach for the development of the bioeconomic analysis. Schnute (1977) formulated the following production model:

$\ln \left(\frac{U_{t+1}}{U_{t}}\right)=b_{0}-b_{1} \frac{\left(U_{t}+U_{t+1}\right)}{2}-b_{2} \frac{\left(E_{t}+E_{t+1}\right)}{2}$

where $U_{t}$ is the catch-per-unit-effort (CPUE) for a year $t, E_{t}$ is the effort for year $t$

$b_{0}=r, \quad b_{1}=\frac{r}{q k}, \quad b_{2}=q$

Clarke et al. (1992) model modified the Fox model by using the Taylor approximation and derived the CYP model as follows:

$\ln \left(U_{t+1}\right)=\operatorname{aln}(q K)+a_{1} \ln \left(U_{t}\right)-a_{2}\left(E_{t}+E_{t+1}\right)$ where $a=\frac{2 r}{(2+r)}, a_{1}=\frac{(2-r)}{(2+r)}$, and $a_{2}=\frac{q}{(2+r)} \mathrm{e}$

Thus, $r=\frac{2\left(1-a_{1}\right)}{\left(1+a_{1}\right)}, q=-a_{2}(2+r)$, and $K=\frac{e^{\frac{a(2+r)}{2 r}}}{\text {. }}$.

The Biological parameters $r, q$, and $K$ are estimated by ordinary least square (OLS) using catch and effort time series data. A bioeconomic model comprises the biological and economic components.

In the biological component, it is assumed that the demersal species in the Straits of Malacca are biologically and ecologically independent. The economic aspect of the bioeconomic model - mainly adopted the method used by Tai (1996), which comprises of revenues and costs of fishing operations where $p$ denotes the constant price of fish, $X(t)$ represents biomass at time $t$, and $C(X(t))$ indicates the cost of yield, which depends on stock abundance. Thus, the net revenues, $\phi(t)$ of commercial harvest $h(t)$ can be written as:

$\phi(t)=[p-C(X(t))] h(t)$

The present value of the net revenue (PV) can be expressed as:

$P V=\int \phi(t) e^{-\mathrm{d} t} d t$

where $d$ is the instantaneous discount rate.

The bioeconomic solution can then be computed using the Maximum principle, the Hamiltonian approach, which produces the basic equation for the bioeconomic solution as below (Clark and Munro, 1975, as cited in Tai, 1996),

$a=F^{\prime}(X(t))-\frac{\left[C^{\prime}(X(t) F(X(t))]\right.}{[p-C(X(t))]}$

where $F^{\prime}(X(t))$ is the rate of change in net growth linked with the growth in the fish stock.

The second item on the right-hand side of Eq. (5) is the incremental stock effect. For biological objectives, fishery managers are mainly concerned about preserving resources and MSY from fish stock. Excessive harvesting beyond the level of MSY will cause the depletion of fish stock. To achieve the maximum biological MSY level of exploitation, this implies that,

$F^{\prime}(X(t))=0$

On the other hand, the economic aspect of fishery management is primarily focused on maximising the economic rent from the fishery by equating the marginal revenue to the marginal cost of fishing. Economic overfishing has occurred if the marginal cost of fishing surpasses the marginal revenue. Tai (1996) pointed out that the maximum economic yield 
(MEY) of fishing is depended on whether future benefits are discounted. If future benefits are all equally important, then the benefit in each period is maximised, which is known as the static maximum economic yield (SMEY), which implies $d$ is equal to 0 , that means the equation(5) can be rewritten as:

$F^{\prime}(X(t))=C^{\prime}(X(t)) F(X(t)) /(P-C(X(t) 0))$

However, when future benefits are discounted, then fishery managers will employ the dynamic maximum economic yield (DMEY) approach. If the discount rate (a) is positive under DMEY - then Eq. (5) is the condition for achieving the DMEY level of harvest (Clarke et al., 1992).

Under an open-access environment, the race for fishing will likely cause the exploitation of fishery to reach the open access equilibrium (OAE) level where total revenue is equal to the total cost of harvesting, driving economic rent to zero in the fishery. Open access equilibrium implies $\mathrm{d}=\infty$ and $O A E$ biomass, $\bar{x}=$ $\frac{c}{p q}$ (Tai, 1996; Clark, 1985, as cited in Clarke et al., 1992). Thus:

$p=C(X(t))$

under the condition of OAE.

Optimal biomass for the CYP model (Clarke et al., 1992) can be determined iteratively by:

$\ln \left(\frac{K}{X^{*}}\right)-\left(1+\frac{\mathrm{a}}{r}\right)\left(1-\frac{\bar{X}}{X^{*}}\right)=0$

where $K$ (carrying capacity), $X^{*}$ (optimal biomass), $r$ (intrinsic growth rate), $a$ (discount rate), $\bar{X}$ (OAE biomass).

Once the values for optimal biomass have been determined for an appropriate range of discount rates, then optimal yield $G\left(X^{*}\right)$ and optimal effort $\left(E^{*}\right)$ can respectively be determined by:

$G\left(X^{*}\right)=r X \ln \left(\frac{K}{X}\right)$

$E^{*}=G\left(X^{*}\right) / q X^{*}$

\section{Catch and effort data}

Different sizes of trawl vessels are employed to capture the marine fisheries resources in the Straits of Malacca. There is a need to standardise fishing effort to reflect the relative change in the fishing power of vessels over time to capture the relative fishing power of these vessels. A relatively small-size trawler of 15.0-24.9 tonnes class was dominant during the study period (30-40\% of trawlers) and operated closer to shore where $80 \%$ of the fishes and crustaceans are concentrated in shallow waters of the Malacca Straits. This small-size trawler was used as the standard vessel for the study period. The formula for standardised effort is written below (Gulland, 1983):

$\sum_{i}^{n} S T E_{i}=\frac{h_{i}}{E_{i}} / \frac{h_{s}}{E_{S}} \times E_{i}$

where $S_{T} E_{i}$ (standardised effort of vessel class $\left.i\right), h_{i}$ (yield of vessel class $i$ ), $E_{i}$ (effort of vessel class $\left.i\right), h_{s}$ (yield of standard vessel), $E_{s}$ (effort of standard vessel). The left-hand side of the equation represents the aggregated sum of standardised effort of all classes of trawlers. The first item on the right-hand side indicates fishing power.

The catch-per-unit-effort is obtained by dividing aggregated harvest of all classes of trawlers by the aggregated standardised effort. Catch and effort time series data of trawl fleet (1-70 tonnes) between 1981 and 2018 were obtained from the Fisheries Department of Malaysia (DOFM)(DOFM, 2020).

Estimates of catch, standardised effort, and catchper-unit-effort of trawl fishery over the 1981-2018 periods are given in Supplementary Table 1.

\section{Harvesting cost and price of fish}

The total cost of harvesting can be expressed as:

$C(E)=c E_{t}$

where $c$ is the constant harvesting cost per standard day. The catch function can be assumed to take the form $h=q E X$, or rearranged to become $E=(h /(q X))$, and thus rewritten as the cost function in terms of fish stock, $C(X)$,

$$
C(X)=c\left(\frac{h}{q X}\right)
$$

Since cost data was not available in the Annual Fisheries Statistics, Malaysia, the cost per standard day was estimated through the author's field survey. The research focused on estimating the cost per standard day of small trawler vessel (15-24.9 tonnes) since the effort of all other trawler types was converted into the standard small trawler day equivalent. Fishing costs were mainly included operating, fixed, labour and opportunity costs. Operating costs cover expenses on fuel, food, and maintenance of vessels and gears. Items included in the fixed costs were depreciation of fixed assets, insurance premiums and license fees. Pays of crew members of trawl vessels were based on sharing (50 $\%$ ) of the net profits from fish sales (Wong and Yong, personal communication, 10 October 2018). Labour cost per vessel was then converted into per standard day equivalent. Capital's opportunity cost was 
reflected by the annualised market value of the trawl vessels (Clarke et al., 1992) in 2018. Once all the cost components were computed, the cost per standard day in 2018 was estimated at MYR1,830 (USD439.2).

Ex-vessel prices were used in the present research since it was directly paid to the fishers. Fish prices tend to change along the logistic supply chain because of added services of intermediaries. The exvessel price was assumed to be constant because individual fishers were price takers whose landings had little effect on market prices. Data on ex-vessel prices of marine landings were estimated using survey data from field research (Wong and Yong, personal communication, 10 October 2018) and published data from the Annual Fisheries Statistics. In 2018, the average price of trawl landings was estimated at MYR7,500 per tonne (USD1,800 per tonne). The economic portion of the bioeconomic model assumed constant price and cost for the harvest of marine resources.

\section{Statistical analysis}

Biological parameters $r, q$, and $K$ were estimated by the ordinary least squares (OLS) regression. Rsquared reveals the goodness-of-fit for a simple linear regression model. T-tests were conducted to test the null hypothesis that both intercept and slope are equal to 0 . The Durbin Watson (DW) test was also conducted to detect any autocorrelation in the residuals from the regression model. The DW statistic usually ranges from 0 to 4 . If the value is 2.0 it means there is no autocorrelation. If values are between 0 and 2, they indicate positive autocorrelation, while values from 2 to 4 reflect negative autocorrelation (Prado et al., 2020). If there is autocorrelation in the residuals, auto-regressive integrated moving average (ARIMA) was used to reduce the effects of this autocorrelation.

\section{Results}

Based on OLS and the 1981-2018 catch and effort data, the trawl fishery in the Straits of Malacca was estimated following Schnute and CYP production models, as shown in Table 1.

The above OLS results show that only the CYP model had the correct signs for the coefficients with a Pvalue significant at the $5 \%$ level; however, the Schnute production model gave unacceptable $\mathrm{R}^{2}$ values. The poor fit of the Schnute model was probably due to the choice of dependent variable (Schnute, 1977, as cited in Tai, 1996). Overall, the CYP model provided a high $\mathrm{R}^{2}$ of the observed data, and Durbin-Watson statistic also showed no autocorrelation problem. Given the OLS results that showed the CYP model fitted the data better than the Schnute model, the coefficients of the CYP model were used to estimate the biological parameters, namely, $r$, q and $K$, for the trawl fishery in the Straits of Malacca (Table 2).

Table 1. Statistical output of the Schnute and ClarkeYoshimoto-Pooley production models for trawl fishery in the Straits of Malacca.

\begin{tabular}{|c|c|c|}
\hline & \multicolumn{2}{|l|}{ Model } \\
\hline & Schnute & Clarke-Yoshimoto-Pooley \\
\hline a & $\begin{array}{l}-0.482 \\
(0.309)\end{array}$ & $\begin{array}{l}2.695 \\
*(0.045)\end{array}$ \\
\hline$b_{1}$ & $\begin{array}{c}0.002 \\
(0.22)\end{array}$ & $\begin{array}{l}0.6 \\
*(0.004)\end{array}$ \\
\hline$b_{2}$ & $\begin{array}{l}2.248 \times 10^{-7} \\
(0.298)\end{array}$ & $\begin{array}{l}-2.619 \times 10^{-7} \\
*(0.05)\end{array}$ \\
\hline$R^{2}$ & 0.046 & 0.865 \\
\hline Adjusted $R^{2}$ & -0.012 & 0.857 \\
\hline DW & $* * 2.735$ & 2.023 \\
\hline
\end{tabular}

*Significant at the $5 \%$ level.

**Perform ARIMA $(1,0,0)$ to correct on the autocorrelation; ARIMA Parameters: $a=-0.363, b_{1}=0.002, b_{2}=2.197 \times 10^{-7}$

Table 2. Biological parameters estimated by the ClarkeYoshimoto-Pooley approach for the trawl fishery in the Straits of Malacca.

\begin{tabular}{lll}
\hline Parameter & Definition & Value \\
\hline$r$ & $\begin{array}{l}\text { Intrinsic growth rate per } \\
\text { year }\end{array}$ & 0.5 \\
$\mathbf{q}$ & $\begin{array}{l}\text { Catchability coefficient } \\
\text { per standardised fishing } \\
\text { day }\end{array}$ & $6.5475 \times 10^{-7}$ \\
& Maximum biomass in & \\
\hline $\mathrm{K}$ & tonnes & \\
\hline
\end{tabular}

Table 2 estimates the intrinsic growth rate per year ( $r$ ) at 0.5 , the catchability coefficient per standardised fishing day (q) and maximum biomass (tonnes) are $6.5475 \times 10^{-7}$ and $1,304,315$, respectively.

Once the various biological parameters were computed, the various bioeconomic parameters such as OAE, SMEY, DMEY, and MSY were estimated (Table 3).

As seen, if fishing occurred at the OAE level, there would be zero economic rent, and this happened when the fishing effort was $3 \%$ higher while the catch was $3 \%$ lower than the mean average effort for the 2014-2018 period.

Table 4 shows that when both SMEY's and DMEY's costs per unit of fishing effort are inflated gradually 
Table 3. Maximum sustainable yield (MSY), open access equilibrium (OAE), static maximum economic yield (SMEY), dynamic maximum economic yield (DMEY), and various bioeconomic levels of biomass, effort, catch, economic rent, and catch-per-uniteffort for trawl fishery in the Straits of Malacca.

\begin{tabular}{lllll}
\hline & Standardised effort(STE) & Catch(C)(Tonnes) & Biomass(X)(Tonnes) & Rent (MYR Mil.) \\
\hline Mean*(2014-2018) & 931,692 & 239,906 & 393272 & 94 \\
OAE & 956,673 & 233,428 & 372,661 & 0 \\
MSY & $(+3 \%)$ & $(-3 \%)$ & $(-5 \%)$ & $(-100 \%)$ \\
& 763,649 & 239,915 & 479,831 & 402 \\
SMEY & $(-18 \%)$ & $(<1 \%)$ & $(+22 \%)$ & $(+428 \%)$ \\
& 396,799 & 201,542 & 775,745 & $(+835 \%)$ \\
DMEY: & $(-57 \%)$ & $(-16 \%)$ & $(+97 \%)$ & 783 \\
d $=0.05$ & & & $(+730 \%)$ \\
& 422,608 & 207,518 & 749,966 & 781 \\
d $=0.10$ & $(-55 \%)$ & $(-14 \%)$ & $(+91 \%)$ & $(+724 \%)$ \\
& 446,534 & 212,503 & 726,833 & 767 \\
d $=0.15$ & $(-52 \%)$ & $(-11 \%)$ & $(+85 \%)$ & $(+714 \%)$ \\
d $=0.20$ & 468,733 & 216,676 & 706,009 & 756 \\
& $(-50 \%)$ & $(-10 \%)$ & $(+80 \%)$ & $(+702 \%)$ \\
\hline
\end{tabular}

*Mean average for catch and effort between 2014-2018 is used as a comparison to estimated optimum biomass, effort, yield, and rent.

Note: Values in brackets represent percentage changes in comparison with the present mean (2014- 2018) level. Conversion rate MYR1.0 = USDO.24.

over time (10-50 \%) from the present base case, the corresponding effort, catch, and rent will reduce progressively from $6 \%$ to $29 \%$, while biomass will increase steadily from $4 \%$ to $20 \%$. Open access equilibrium shows similar fluctuation patterns but with a relatively greater proportion of changes: effort, catch, and rent will decline from $7 \%$ to $73 \%$, whereas biomass will increase from $10 \%$ to $50 \%$, however, economic rent will remain at zero.

Likewise, Table 5 shows that when SMEY's and DMEY's ex-vessel prices are inflated from $10 \%$ to $50 \%$ over time, this will cause a modest progressive increase in fishing effort and catch (3-25\%) as well as biomass (3-11\%), but will result in a significant increase in economic rents (19-101\%). The impact of elevated exvessel price on OAE's bioeconomic parameters will be relatively more significant for effort (8-132\%), but a modest increase for catch (8-32\%) and biomass (9-33 $\%)$, but rent will stay the same at zero.

\section{Discussion}

The chief goal of fishery managers is to determine the maximum biological sustainable yield and maximum economic yield from the fishery. Often, fishery authority is forced to make tough management goals based on minimal biological and economic data, especially in a multi-species fishery. Surplus production models may prove to be useful in developing fishery because they require minimal data. The preceding section shows that only the CYP model best fits the catch and effort data for trawl fishery in the Straits of Malacca. The coefficients of the model are also statistically significant. Hence the CYP model is used to compute the biological parameters, employed to estimate maximum bioeconomic yields. The model provides useful biological parameters and reasonable economic estimates for the Straits of Malacca trawl's fishery. This paper shows that the present exploitation level of trawl fishery in the Straits of Malacca is very near to the OAE level, where economic rent will be driven to zero (see Table 3). Similarly, the results also indicated that the present level of exploitation had far exceeded the MSY and bioeconomic levels implied that biological and economic overfishing by the trawl fishery has already occurred in the straits. The fishery can be revitalised if the fishing effort can be scaled down to the MSY or the bioeconomic level of exploitation. If the fishing effort is cut by $18 \%$ to the MSY exploitation level, the yield will remain about the same, but biomass and economic rent can be increased by $22 \%$ to $28 \%$, respectively.

A comparison with the optimum bioeconomic level shows that if the present status of exploitation can be reduced between $50 \%$ and $59 \%$, then yield might drop slightly somewhere between $9 \%$ and $17 \%$, but biomass will increase by about 79-100 \%, and rent can increase tremendously by more than $800 \%$, from the present figures. If the fishing effort is scaled down to SMEY level, biomass can be doubled to 789,585 tonnes while resource rent increases from MYR94 million to MYR785 million (USD22.56-USD188.4 million) or an upsurge of $834 \%$. When different discount rates are applied to the bioeconomic model, they produce diverse but predictable DMEY results. When the 
Table 4. The impact of inflated cost per unit effort on open access equilibrium (OAE), static maximum economic yield (SMEY), and dynamic maximum economic yield (DMEY) in the Malacca Straits' trawl fishery.

\begin{tabular}{|c|c|c|c|c|c|}
\hline & \multicolumn{5}{|c|}{ Inflated cost per standard unit effort (MYR/STE) } \\
\hline & Base case & $+10 \%$ & $+20 \%$ & $+30 \%$ & $+50 \%$ \\
\hline \multicolumn{6}{|l|}{ OAE: } \\
\hline Biomass & 372,661 & 409,927 & 447,194 & 484,460 & 558,992 \\
\hline Catch & 233,428 & 237,236 & 239,347 & 239,904 & 236,816 \\
\hline Effort & 956,673 & 883,889 & 817,443 & 756,318 & 647,039 \\
\hline Rent & 0 & 0 & 0 & 0 & 0 \\
\hline \multicolumn{6}{|l|}{ SMEY: } \\
\hline Biomass & 775,745 & 800,651 & 825,055 & 848,999 & 895,651 \\
\hline Catch & 201,542 & 195,362 & 188,931 & 182,270 & 168,330 \\
\hline Effort & 396,799 & 372,667 & 349,739 & 327,892 & 287,042 \\
\hline Rent (MYR Million) & 785 & 715 & 649 & 587 & 475 \\
\hline \multicolumn{6}{|l|}{ DMEY: } \\
\hline \multicolumn{6}{|l|}{$\mathrm{d}=0.05$} \\
\hline Biomass & 749,966 & 776,178 & 801,842 & 827,006 & 875,999 \\
\hline Catch & 207,518 & 201,438 & 195,057 & 188,401 & 174,354 \\
\hline Effort & 422,608 & 396,373 & 371,532 & 347,935 & 303,985 \\
\hline $\begin{array}{l}\text { Rent (MYR Million) } \\
\mathrm{a}=0.10\end{array}$ & 783 & 713 & 647 & 585 & 473 \\
\hline Biomass & 726,833 & 754,203 & 780,985 & 807,232 & 858,306 \\
\hline Catch & 212,503 & 206,565 & 200,275 & 193,664 & 179,589 \\
\hline Effort & 446,534 & 418,306 & 391,659 & 366,416 & 319,566 \\
\hline $\begin{array}{l}\text { Rent (MYR Million) } \\
\mathrm{d}=0.15\end{array}$ & 777 & 707 & 642 & 581 & 470 \\
\hline Biomass & 706,009 & 734,406 & 762,179 & 789,390 & 842,319 \\
\hline Catch & 216,676 & 210,911 & 204741 & 198,205 & 184,162 \\
\hline Effort & 468,733 & 438,619 & 410,272 & 383,484 & 333,925 \\
\hline $\begin{array}{l}\text { Rent (MYR Million) } \\
\mathbf{d}=0.20\end{array}$ & 767 & 699 & 635 & 574 & 465 \\
\hline Biomass & 687,205 & 716,512 & 745,167 & 773,235 & 827,819 \\
\hline Catch & 220,181 & 214,609 & 208,581 & 202,143 & 188,179 \\
\hline Effort & 489,348 & 457,456 & 427,510 & 399,274 & 347,185 \\
\hline Rent (MYR Million) & 756 & 689 & 626 & 566 & 458 \\
\hline
\end{tabular}

Conversion rate MYR1.0 = USDO.24.

Table 5. The impact of inflated ex-vessel prices on open access equilibrium (OAE), static maximum economic yield (SMEY), and dynamic maximum economic yield (DMEY) in Malacca Straits' trawl fishery.

\begin{tabular}{|c|c|c|c|c|c|}
\hline & \multicolumn{5}{|c|}{ Ex-vessel price (MYR / Tonne) } \\
\hline & Base case & $+10 \%$ & $+20 \%$ & $+30 \%$ & $+50 \%$ \\
\hline \multicolumn{6}{|l|}{ OAE: } \\
\hline Biomass & 372,661 & 338,783 & 310,551 & 286,663 & 248,441 \\
\hline Catch & 233,428 & 228,352 & 222,834 & 217,165 & 205,986 \\
\hline Effort & 956,673 & $1,029,457$ & $1,095,903$ & $1,157,028$ & $1,266,307$ \\
\hline Rent & 0 & 0 & 0 & 0 & 0 \\
\hline \multicolumn{6}{|l|}{ SMEY: } \\
\hline Biomass & 775,745 & 756,625 & 732,979 & 716,061 & 688,379 \\
\hline Catch & 201,542 & 206,921 & 211,214 & 214,699 & 219,969 \\
\hline Effort & 396,799 & 419,905 & 440,104 & 457,936 & 488,044 \\
\hline Rent (MYR & 785 & 939 & 1,096 & 1,255 & 1,582 \\
\hline Million) & & & & & \\
\hline \multicolumn{6}{|l|}{ DMEY: } \\
\hline \multicolumn{6}{|l|}{$\mathrm{d}=0.05$} \\
\hline Biomass & 749,966 & 725,612 & 704,897 & 687,044 & 657,793 \\
\hline Catch & 207,518 & 212,756 & 216,890 & 220,210 & 225,144 \\
\hline Effort & 422,608 & 447,818 & 469,936 & 489,527 & 522,751 \\
\hline $\begin{array}{l}\text { Rent (MYR } \\
\text { Million) }\end{array}$ & 783 & 936 & 1,092 & 1,251 & 1,576 \\
\hline
\end{tabular}




\begin{tabular}{|c|c|c|c|c|c|}
\hline & \multicolumn{5}{|c|}{ Ex-vessel price (MYR / Tonne) } \\
\hline & Base case & $+10 \%$ & $+20 \%$ & $+30 \%$ & $+50 \%$ \\
\hline \multicolumn{6}{|l|}{$\mathrm{d}=0.10$} \\
\hline Biomass & 726,833 & 701,385 & 679,724 & 661,041 & 630,400 \\
\hline Catch & 212,503 & 217,561 & 221,504 & 224,627 & 229,175 \\
\hline Effort & 446,534 & 473,750 & 497,706 & 518,989 & 555,234 \\
\hline $\begin{array}{l}\text { Rent (MYR } \\
\text { Million) } \\
\mathbf{d}=0.15\end{array}$ & 777 & 928 & 1,083 & 1,240 & 1,562 \\
\hline Biomass & 706,009 & 679,593 & 657,095 & 637,679 & 605,807 \\
\hline Catch & 216,676 & 221,527 & 225,254 & 228,161 & 232,288 \\
\hline Effort & 468,733 & 497,853 & 523,562 & 546,466 & 585,622 \\
\hline $\begin{array}{l}\text { Rent (MYR } \\
\text { Million) } \\
\mathbf{d}=0.20\end{array}$ & 767 & 917 & 1,069 & 1,225 & 1,541 \\
\hline Biomass & 687,205 & 659,932 & 636,695 & 616,631 & 583,674 \\
\hline Catch & 220,181 & 224,805 & 228,300 & 230,978 & 234,663 \\
\hline Effort & 489,348 & 520,272 & 547,646 & 572,097 & 614,044 \\
\hline $\begin{array}{l}\text { Rent (MYR } \\
\text { Million) }\end{array}$ & 756 & 903 & 1,053 & 1,205 & 1,516 \\
\hline
\end{tabular}

Conversion rate MYR1.0 = USD0.24.

discount rate increases gradually from $5 \%$ to $20 \%$; the corresponding fishing effort increases from 422,608 days to 489,348 days, respectively. Nevertheless, these levels of exploitation are still very much lower than the present level. However, when there is a gradual increase in the discount rate, the corresponding yield, biomass, and the economic rent of DMEY will decrease accordingly.

Another advantage of using the bioeconomic model is that we can analyse the impact of increasing cost per unit of effort and ex-vessel price on the exploitation level of trawl fishery under open access environment in the Straits of Malacca. In the absence of management, the fishery will move toward OAE, where economic rent is driven down to zero. Any changes in costs and prices will affect the OAE bioeconomic parameters, and the same apply to MEY's fishing effort, catch, biomass, and economic rent.

In the late 1990s, Ahmad et al. (2003), by using the Fox model, estimated the MSY of demersal species in the Straits of Malacca at around 273,000 tonnes based on trawl research data. The results showed that the MSY level of the demersal fish population was reached in 1994. Our CYP model estimated a relatively lower MSY of 239,915 tonnes. Tai (1996) fitted the CYP model on the 1969-1991 catch and effort data of the demersal fishery in the northern region of the Straits of Malacca. His results showed that the catch and effort of OAE were at 43,061 tonnes and 1.46 million standard days (based on a standard trawler with less than 40 tonnes), respectively. Our studies showed an OAE's effort at a comparatively lower level of 0.96 million standard days and a relatively much higher catch at 233,428 tonnes for the aggregated species (demersal, pelagic, and crustacean) in the Straits for the 1981-2018 period. Tai's (1996) research also showed that the economic rent at MEY was around MYR1,935 million (USD464.4 million) achieved through 285,758 standard fishing days. However, our research estimated MEY's economic rent at MYR785 million (USD188.4 million), which is significantly lower than Tai's estimation while exerting relatively higher fishing effort (396,799 standard days) for the more recent catch and effort 1981-2018 time-series data. The current study shows that MEY and corresponding economic rents are relatively unresponsive to discount rates which are quite consistent with the findings of Tai (1996) and Clarke et al. (1992). Moe et al. (2019) simulated results also indicated that trawl fishing in zone B was overexploited in 2012 and needed to be reduced by half from the base year level so that the marine resources can be fished at an economically feasible level.

Nesslage and Wilberg (2012), however, opined that applying a single-species surplus production model (SSPM) to a heterogenous species fishery may not be appropriate because of catchability, life history, and fishing pressure varied among the individual species in an assemblage. To overcome this problem, incorporating time-varying parameters (growth or catchability) may help capture resulting changes in assemblage dynamics and improve model prediction. Schaefer SSPM models, with and without timevarying catchability and growth rate, were fitted to simulated data to estimate MSY and effort at MSY of heterogenous species (Nesslage and Wilberg, 2012). All models showed biased estimates but incorporating time-changing parameters improved the accuracy of 
the MSY of multi-species assemblage. However, the improved results may produce direction and magnitude of bias unless diverse growth rates and catchability of heterogenous species in the fishery are known.

Similarly, Fogarty et al. (2012) fitted surplus production models to 12 demersal fish species in the Gulf of Maine at the single-species and aggregatespecies levels. The results indicated that MSY and yield at MSY for the combined single-species production model exceeded the aggregate-species model by $27.5 \%$ and $28 \%$, respectively. The Extended Production model that incorporated climate change also showed inconclusive results. However, Fogarty et al. (2012) suggested a need to develop a more dynamic production model to account for environmental factors, given that past scientific results had shown that there is a link between climate change and fishery productivity.

Overall, this paper shows that the trawl fishery in the Straits of Malacca has been overexploited and an effort reduction strategy needs to be implemented. If fishing effort can be reduced somewhere between 20-40 per cent from the current exploitation level, resource rent could have increased by 400-800\% based on current unit cost and ex-vessel prices. The fishery authority can review and refine existing protective fishing policies to balance conflicting interests of commercial fishing, artisanal fishing, ecosystems management, eco-tourism, and subsidy programs, to promote sustainable fishing. The lack of enforcement on illegal, unreported, and unregulated fishing must also be addressed to reduce excessive fishing. Without an effective and efficient regulatory and enforcement system, trawl fishing will become unsustainable and the livelihood and income of those who depend on it will be badly affected.

Though the CYP model seems to have a good fit giving reasonable results, the analysis assumes the trawl fishery as one aggregated stock instead of separating into different major species. If a model can incorporate the biological (growth rate and catchability) and economic (varied prices and costs for different species) differences of the multi-species - in that case, it can improve further the management of the heterogenous species in the trawl fishery.

\section{Conclusion}

This paper provides useful bioeconomic parameters for the fishery authority to properly manage the trawl fishery in the Straits of Malacca. The present study results showed that the trawl fishery in the Straits of Malacca had been overfished. There is a need to revise existing policies, including a recent subsidy policy, to create a balance between protecting reasonable fishers' income and waning fisheries resources due to overfishing. The Government may consider encouraging less successful fishers to diversify into other more rewarding areas such as eco-tourism, aquaculture, and hospitality services. The sensitivity analysis on inflated prices also shows disturbing outcomes because increasing fish prices over time due to increased human population, greater awareness of health benefits derived from fish consumption, income growth, and other demand push factors. All these can quickly deplete local marine resources. The fishery authority needs to take note of these demand forces and manage the trawl fishery prudently, particularly to control the overfishing of high-priced commercial species. This issue needs to be addressed or it might lead to stock crash such as the 1992 cod fishery case in Canada's east coast where cod biomass fell to one per cent of its earlier level (Hamilton and Butler, 2001).

\section{Acknowledgements}

We want to thank the two anonymous reviewers, Prof. Chong Ving Ching and Prof. Ong Seng Huat, for providing critical reading and useful comments for the manuscript.

Conflict of interest: The authors declare that they have no conflict of interest.

\section{References}

Ahmad, A.T., Isa, M.M., Ismail, M.S., Yusof, S. 2003. Status of demersal fishery resources of Malaysia. In: Assessment, management and future directions for coastal fisheries in Asian countries. WorldFish Center conference proceedings. (Eds. Silvestre, G., Garces, L., Stobutzki, I., Ahmed, M., Valmonte-Santos, R.A., Luna, C., LachicaAliño, L., Munro, P., Christensen, V., Pauly, D.), pp. 83-136. http://pubs.iclarm.net/resource_centre/AMF_Chapter-05-FA.pdf

Clark, C.W., Munro, G.R. 1975. The economics of fishing and modern capital theory: a simplified approach. Journal of Environmental Economics and Management 2:92-106. https://doi.org/10.1016/00950696(75)90002-9

Clark, C.W. 1985. Bioeconomic modeling and fisheries management. Wiley, New York. 291 pp.

Clarke, R.P., Yoshimoto, S.S., Pooley, S.G. 1992. A bioeconomic analysis of the Northwestern Hawaiian islands lobster fishery. Marine Resource Economics 7:115-140.

Department of Fisheries Malaysia. 2020. Annual Fisheries Statistics 1981-2020. https://www.dof.gov.my/

Fogarty, M., Overholtz, W.J., Link, J.S. 2012. Aggregate surplus production models for demersal fishery resources of the Gulf of Maine. Marine Ecology Progress Series 459:247-258. https://doi.org/10.3354/meps09789

Gulland, J.A. 1983. Fish stock assessment: a manual of basic methods. Wiley Interscience, Chichester, $223 \mathrm{pp}$.

Hamilton, L.C., Butler, M.J. 2001. Outport adaptations: social indicators through Newfoundland's cod crisis. Human Ecology Review 8:1-11.

Moe, S.S., Tai, S.Y., Mohammed, N.K. 2019. Effort dynamics and alternative management policies: the case of the west coast zone $B$ trawl fishery in peninsular Malaysia. Marine Resource Economics 34:77-103. https://doi.org/10.1086/702268

Nesslage, G.M., Wilberg, M.J. 2012. Performance of surplus production models with time-varying parameters for assessing multispecies assemblages. North American Journal of Fisheries Management 
32:1137-1145. https://doi.org/10.1080/02755947.2012.720646

Prado, T.K.L.D., Savian, T.V., Fernandes, T.J., Muniz, J.A. 2020. Study on the growth curve of the internal cavity of 'Dwarf green' coconut fruits. Revista Ciência Agronômica 51:1-7. https://doi.org/10.5935 /1806-6690.20200041

Ramli, M. 2015. False alarm: is fishing rezoning necessary in Malaysia. IOSR Journal of Agriculture and Veterinary Science 8:58-63. https://doi.org/10.9790/2380-081125863

Schnute, J. 1977. Improved estimates from the Schaefer production model: theoretical considerations. Journal of the Fisheries
Research Board of Canada 34:583-603. https://doi.org/10.1139/f77094

Tai, S.Y. 1996. Optimal bioeconomic exploitation of the demersal fishery in northwest peninsular Malaysia. Pertanika Journal of Social Sciences \& Humanities 4:65-76. https://doi.org/10.1086 /mre.11.2.42629148

Wong, H.S., Yong, C.C. 2020. Fisheries regulation: a review of the literature on input controls, the ecosystem, and enforcement in the Straits of Malacca of Malaysia. Fisheries Research 230:105682. https://doi.org/10.1016/j.fishres.2020.105682 
Supplementary Table 1. Catch, standardised effort, and catch-per-unit-effort of trawler fleet of the Straits of Malacca, $1981-$ 2018.

\begin{tabular}{|c|c|c|c|}
\hline Year & Catch (tonnes) & Standardised effort in days (STE) & Catch-per-unit-effort measured in kg.day-1 (CPUE) \\
\hline 1981 & 78979 & 2121956 & 37.22 \\
\hline 1982 & 94229 & 1794853 & 52.50 \\
\hline 1983 & 94274 & 1917302 & 49.17 \\
\hline 1984 & 77816 & 2448989 & 31.77 \\
\hline 1985 & 81296 & 2150051 & 37.81 \\
\hline 1986 & 84774 & 1783961 & 47.52 \\
\hline 1987 & 137417 & 2327784 & 59.03 \\
\hline 1988 & 129464 & 2132771 & 60.70 \\
\hline 1989 & 135242 & 1885715 & 71.72 \\
\hline 1990 & 143670 & 1851971 & 77.58 \\
\hline 1991 & 123788 & 2187289 & 56.59 \\
\hline 1992 & 151687 & 1591357 & 95.32 \\
\hline 1993 & 122717 & 1536536 & 79.87 \\
\hline 1994 & 125816 & 1829802 & 68.76 \\
\hline 1995 & 150059 & 1923939 & 78.00 \\
\hline 1996 & 149897 & 1524276 & 98.34 \\
\hline 1997 & 149506 & 1712663 & 87.29 \\
\hline 1998 & 155742 & 1617162 & 96.31 \\
\hline 1999 & 136272 & 1381254 & 98.66 \\
\hline 2000 & 150174 & 1018327 & 147.47 \\
\hline 2001 & 122209 & 1289525 & 94.77 \\
\hline 2002 & 133533 & 1334796 & 100.04 \\
\hline 2003 & 128650 & 1375701 & 93.52 \\
\hline 2004 & 130458 & 1465631 & 89.01 \\
\hline 2005 & 118174 & 1635006 & 72.28 \\
\hline 2006 & 162623 & 1678950 & 96.86 \\
\hline 2007 & 169845 & 1591422 & 106.73 \\
\hline 2008 & 177064 & 1538527 & 115.09 \\
\hline 2009 & 196439 & 1434502 & 136.94 \\
\hline 2010 & 215813 & 1019387 & 211.71 \\
\hline 2011 & 217038 & 1099875 & 197.33 \\
\hline 2012 & 221290 & 958903 & 230.77 \\
\hline 2013 & 200263 & 1132474 & 176.84 \\
\hline 2014 & 231263 & 970069 & 238.40 \\
\hline 2015 & 222280 & 979157 & 227.01 \\
\hline 2016 & 244777 & 1001933 & 244.30 \\
\hline 2017 & 237658 & 903794 & 262.96 \\
\hline 2018 & 263550 & 803506 & 328.00 \\
\hline
\end{tabular}

